\title{
Importance of Artificial Intelligence in Reverse Logistics: The State of the Art
}

\author{
Tolga Temucin*, Ozalp Vayvay, Fulya Callialp Kunter
}

\begin{abstract}
The primary target in this study is to present the tendency of academicians and practitioners towards the reverse logistics (RL) issue. Hence, the literature related to the issue is examined in detail and at the end of the study some valuable information is gathered according to the distribution of artificial intelligence (AI) techniques in various segments of RL. Based on the results presented, it'll be appropriate to decide whether it is a necessity to continue considering the $R L$ concept in managerial processes or not.
\end{abstract}

Keywords-reverse logistics, artificial intelligence, metaheuristics

\section{Introduction}

RL has been defined as the movement of product or materials in the opposite direction for the purpose of creating or recapturing value, or for proper disposal [1]. Although the tendency toward RL concept is increasing nowadays, it is currently attracts less attention than needed because to deal with a cost-intensive activity does not take place among the priorities of a company. According to a survey conducted in 1997, the RL cost amounted to approximately $\$ 35$ billion which is around $4 \%$ of the total logistics cost in the same year [2]. However, companies with the right RL practices can increase up to $5 \%$ of their earnings [3]. Companies have begun to realize this fact recently. Additionally, RL practices have become necessary not only for cost concerns but also for increasing level of global competition, heightened environmental regulations, improved corporate image opportunities, etc. The justification for introducing RL into organizations is not a trivial decision. Introducing $\mathrm{RL}$ is a strategic decision requiring evaluation of a broad set of criteria, including strategic, operational, tangible, and intangible dimensions [4]. Several reasons forming the basis of this strategic decision are competitive reasons, legal disposal issues and Good Corporate Citizenship.

As [5] point out, RL is not necessarily a symmetric picture of forward distribution. Table 1 summarizes the differences between reverse and forward logistics. The differences existing between the two distribution channels cause RL to be managed with great difficulty. RL problems are classified in NP-hard class of problems [6 - 12]. [13] expressed that due to the NP-hard nature of the problems, efficient solving of these problems within a reasonable time for large instances requires adoption of effective heuristic and meta-heuristic approaches.

Tolga Temucin, Ozalp Vayvay, Fulya Callialp Kunter

Marmara University

Turkey
The remainder of this study is structured as follows. The survey methodology used in this paper is outlined and the results of the survey are presented next. Finally, conclusions and further recommendations are highlighted in the last section.

\section{Survey Methodology}

During the review, ScienceDirect, SpringerLinks, and Emerald databases had been investigated to search for the keywords. The keywords are classified into two categories, namely AI and RL, for the sake of the research. Thus, the literature is examined by the two groups of keywords respectively to cross-search the related journal publications. In this research, 88 papers which were published during the 2008-2013 period had been examined. The papers found from the aforementioned databases had been identified, analyzed, classified, and recorded under a classification scheme that includes the method(s) applied, application area(s).

\section{Results of Literature Survey}

\section{A. Distribution of AI Techniques in Various Segments of $R L$}

Based on the problems concerned in the articles, they were classified into four subcategories, namely, network design problems, vehicle routing problems, preference problems, and other issues.

- Network design problems: A network having both forward and reverse channels contains some of the supply chain components such as retailers, suppliers, manufacturers, customers/consumers, collection centers, repair centers, hybrid processing facilities, disposal centers, etc. [15 - 16] stated that few studies have addressed the problem of determining the number and location of repair facilities where returned products from retailers or end-customers were inspected, repaired, and refurbished for redistribution. [17] proposed a hybrid approach integrating fuzzy concept and genetic algorithm for a network design problem. [18] proposed a multi-objective optimization model in which maximization of satisfaction level of trade, maximization of satisfaction degrees of customers, and maximization of total closed-loop supply chain (CLSC) profit objectives exist. The general list of the studies concerning this subject is presented in Table 1. According to the distribution of AI techniques in this sub-category, GA and FS are the most popular techniques as shown in Fig. 1. 
Proc. of The Sixth Intl. Conf. On Advances in Applied Science and Environmental Technology - ASET 2017 Copyright (C) Institute of Research Engineers and Doctors, USA .All rights reserved.

ISBN: 978-1-63248-119-1 doi: 10.15224/ 978-1-63248-119-1-35

TABLE I. DISTRIBUTION OF AI TECHNIQUES IN NETWORK DESIGN PROBLEMS

\begin{tabular}{|l|l|}
\hline AI Method & \multicolumn{1}{|c|}{ Summary of the Literature } \\
\hline FS & {$[17-18],[21],[23-30]$} \\
\hline GA & {$[8],[15-16],[17],[19-20],[26],[31-38]$} \\
\hline MA & {$[9],[22],[39]$} \\
\hline AIS & {$[34]$} \\
\hline NS & {$[13],[40]$} \\
\hline SS & {$[41]$} \\
\hline SA & {$[10],[42-43]$} \\
\hline TS & {$[11-12],[44-45]$} \\
\hline PSO & {$[38],[46]$} \\
\hline
\end{tabular}

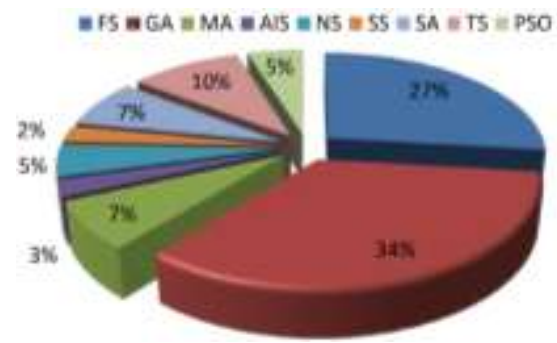

Figure 1. Frequency of AI techniques in network design problems

- Vehicle routing problems: Vehicle routing problem (VRP) in which the target is to minimize the cost of distributing the goods to a number of customers with a fleet of vehicles, is one of the popular issues within RL subject. For example, [47] introduced the strategy of information update via Ant Colony Systems to solve the VRPSDP problem with limited maximum distance. [48] developed a mixed integer programming model. [49] studied the VRPSDP problem having its special feature. [50] studied VRP and the inventory control decision problem simultaneously which is because they believed that the two problems affect each other and must be considered together. Table 2 summarizes the AI approaches used in this subcategory. According to the distribution of AI techniques TS is the most popular tool used in the VRPs' solution procedure as shown in Fig. 2.

TABLE II. DISTRIBUTION OF AI TECHNIQUES IN VEHICLE ROUTING PROBLEMS

\begin{tabular}{|c|l|}
\hline AI Method & \multicolumn{1}{|c|}{ Summary of the Literature } \\
\hline ACO & {$[47],[54-55]$} \\
\hline GA & {$[48]$} \\
\hline DEA & {$[56]$} \\
\hline TS & {$[49-50],[52],[57-59]$} \\
\hline NS & {$[51]$} \\
\hline PSO & {$[60-61]$} \\
\hline SA & {$[62-63]$} \\
\hline GRASP & {$[53]$} \\
\hline
\end{tabular}

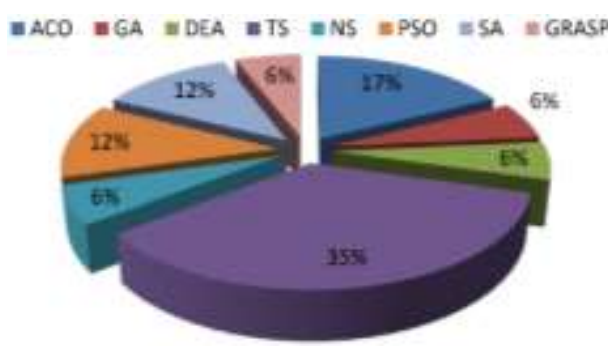

Figure 2. Frequency of AI techniques in VRP
- Preference problems: [64] proposed a hybrid methodology based on AHP and fuzzy TOPSIS for the evaluation and selection of RL operating channels. [65] evaluated three different collecting modes (reverse channels) in RSCM. [66] introduced green criteria into the framework of supplier selection issue. [67] investigated the consideration factors of RL implementation. Based on characteristics of electronic products' recycling and reuse. Table 3 summarizes the AI approaches used in this subcategory. Among various methodologies FS is the most popular tool used in preference problems as shown in Fig. 3.

TABLE III. DISTRIBUTION OF AI TECHNIQUES IN PREFERENCE PROBLEMS

\begin{tabular}{|c|l|}
\hline AI Method & \multicolumn{1}{|c|}{ Summary of the Literature } \\
\hline FS & {$[34],[64-65],[67],[69-79]$} \\
\hline CBR & {$[7]$} \\
\hline ANN & {$[70]$} \\
\hline GA & {$[66],[71]$} \\
\hline ABC & {$[68]$} \\
\hline PSO & {$[80]$} \\
\hline
\end{tabular}

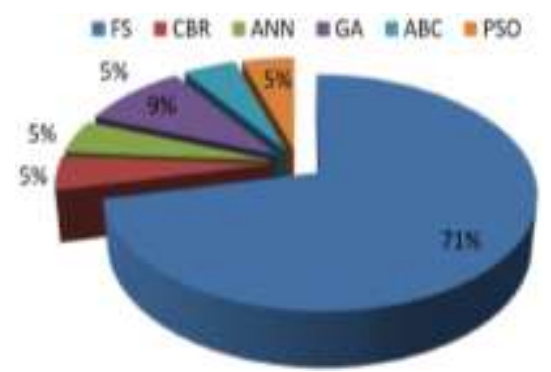

Figure 3. Frequency of AI techniques in preference problems

- Other issues: [81] developed two models in which one of them had a constant rate of defectiveness while the other had its fuzzy version. [82] presented a multi-criteria decision model to determine prices of reusable and recyclable components to maximize revenue and minimize product recovery costs. [83] looked for a disassembly sequence plan in two steps. [84] searched to balance a paced disassembly line considering sequence dependency. [85] considered the capacitated production planning problem within which all demands are met by production. [86] proposed a generic forecasting framework for product returns. [87] defined the reverse MRP algorithm and [88 - 90] considered the disassembly line balancing problem. Table 4 summarizes the AI approaches used in this subcategory.

TABLE IV. DISTRIBUTION OF AI TECHNIQUES IN OTHER ISSUES

\begin{tabular}{|c|l|}
\hline AI Method & \multicolumn{1}{|c|}{ Summary of the Literature } \\
\hline GA & {$[81-82],[85],[91]$} \\
\hline FS & {$[81],[87],[91]$} \\
\hline GRASP & {$[83]$} \\
\hline MAS & {$[92-93]$} \\
\hline ACO & {$[84],[89]$} \\
\hline BN & {$[86]$} \\
\hline PSO & {$[88]$} \\
\hline RL & {$[90]$} \\
\hline SA & {$[94]$} \\
\hline
\end{tabular}




\section{Iv. Conclusions and Further Recommendations}

This study has presented an extensive review consisting of 88 papers from 40 scholarly journals on the usage of AI methodologies within RL concept. During the review process, a classification scheme was developed to organize each paper into several categories. Papers were categorized based on methods used, and application areas. According to the review, the findings are given as follows:

- The three subjects used extensively within RL concept are network design problems, vehicle routing problems, and preference problems.

- GA and FS are the most popular methods used in network design problems while TS and FS are the most popular ones respectively in VRPs and preference problems.

Based on the review, the complex nature of RL problems frequently requires multi-objective optimization. Therefore, AI seems to be a promising tool for these problems. But still, there are some certain aspects in RL that have not been fully addressed and also several AI methodologies that are not employed yet. This is surely a future direction for both research subjects: AI and RL.

\section{References}

[1] Tibben-Lembke, R. S., and D. S. Rogers. 2002. "Differences between Forward and Reverse Logistics in a Retail Environment." Supply Chain Management: An International Journal 7 (5): 271-282. doi: 10.1108/13598540210447719.

[2] Rogers, D. S., and R. S. Tibben-Lembke. 1998. Going backwards: reverse logistics trends and practices. Reno, NV: Reverse Logistics Executive Council.

[3] Greve, C., and J. Davis. 2012. An executive's guide to reverse logistics: how to find hidden profits by managing returns!

[4] Presley, A., L. Meade, and J. Sarkis. 2007. "A Strategic Sustainability Justification Methodology for Organizational Decisions: A Reverse Logistics Illustration." International Journal of Production Research 45 (18-19): 4595-4620. doi: 10.1080/00207540701440220.

[5] Fleischmann, Moritz, Jacqueline M. Bloemhof-Ruwaard, Rommert Dekker, Erwin van der Laan, Jo A. E. E. van Nunen, and Luk N. Van Wassenhove. 1997. "Quantitative Models for Reverse Logistics: A Review." European Journal of Operational Research 103 (1): 1-17. doi: 10.1016/S0377-2217(97)00230-0.

[6] Hauser, W. M., and R. T. Lund. 2008. Remanufacturing operating practices and strategies. Boston, Massachusetts, USA: Technical report published by Boston University.

[7] Ziout, A., A. Azab, and M. Atwan. 2014. "A Holistic Approach for Decision on Selection of End-of-Life Products Recovery Options." Journal of Cleaner Production 65: 497-516. doi: 10.1016/j.jclepro.2013.10.001.

[8] [8] Wang, H.-F., and H.-W. Hsu. 2010. "A Closed-Loop Logistic Model with a Spanning-Tree Based Genetic Algorithm." Computers $\begin{array}{llll}\text { \& Operations } \quad \text { Research } 37 \text { (2): 376-389. doi } & \end{array}$ 10.1016/j.cor.2009.06.001.

[9] Pishvaee, M. S., R. Z. Farahani, and W. Dullaert. 2010a. "A Memetic Algorithm for Bi-Objective Integrated Forward/Reverse Logistics Network Design." Computers \& Operations Research 37 (6): 11001112. doi: 10.1016/j.cor.2009.09.018.

[10] Lee, D.-H., and M. Dong. 2009. "Dynamic Network Design for Reverse Logistics Operations Under Uncertainty." Transportation Research Part E 45 (1): 61-71. doi: 10.1016/j.tre.2008.08.002.

[11] Aras, N., and D. Aksen. 2008. "Locating Collection Centers for Distance- and Incentive-Dependent Returns.” International Journal of
Production Economics doi:10.1016/j.ijpe.2007.01.015.

111

$(2)$

316-333.

[12] Aras, N., D. Aksen, and A. G. Tanuğur. 2008. "Locating Collection Centers for Incentive-Dependent Returns Under a Pick-Up Policy with Capacitated Vehicles." European Journal of Operational Research 191 (3): 1223-1240. doi:10.1016/j.ejor.2007.08.002.

[13] Eskandarpour, M., S. H. Zegordi, and E. Nikbakhsh. 2013a. "A Parallel Variable Neighborhood Search for the Multi-Objective Sustainable Post-Sales Network Design Problem." International Journal of Production Economics 145 (1): 117-131. doi: 10.1016/j.ijpe.2012.10.013.

[14] Xing, B., W.-J. Gao, K. Battle, T. Marwala, and F. V. Nelwamondo. 2010. Artificial intelligence in reverse supply chain management: the state of the art. Paper presented at the meeting of the Twenty-first Annual Symposium of the Pattern Recognition Association of South Africa, Stellenbosch, South Africa, pp.305-310.

[15] Min, H., and H.-J. Ko. 2008. "The Dynamic Design of a Reverse Logistics Network from the Perspective of Third-Party Logistics Service Providers." International Journal of Production Economics 113 (1): 176-192. doi: 10.1016/j.ijpe.2007.01.017.

[16] Liu, D. 2014. "Network Site Optimization of Reverse Logistics for ECommerce Based on Genetic Algorithm." Neural Computing and Applications 25 (1): 67-71. doi: 10.1007/s00521-013-1448-1.

[17] Qin, Z., and X. Ji. 2010. "Logistics Network Design for Product Recovery in Fuzzy Environment.” European Journal of Operational Research 202 (2): 479-490. doi: 10.1016/j.ejor.2009.05.036.

[18] Özkır, V., and H. Başlıgil. 2013. "Multi-Objective Optimization of Closed-Loop Supply Chains in Uncertain Environment." Journal of Cleaner Production 41: 114-125. doi: 10.1016/j.jclepro.2012.10.013.

[19] Kannan, G., P. Sasikumar, and K. Devika. 2010. "A Genetic Algorithm Approach for Solving a Closed Loop Supply Chain Model: A Case of Battery Recycling." Applied Mathematical Modelling 34 (3): 655-670. doi: 10.1016/j.apm.2009.06.021

[20] Lee, C. K. M., and T. M. Chan. 2009. "Development of RFID-Based Reverse Logistics System.” Expert Systems with Applications 36 (5): 9299-9307. doi: 10.1016/j.eswa.2008.12.002.

[21] Pishvaee, M. S., and S. A. Torabi. 2010. "A Possibilistic Programming Approach for Closed-Loop Supply Chain Network Design Under Uncertainty." Fuzzy Sets and Systems 161 (20): 26682683. doi: 10.1016/j.fss.2010.04.010.

[22] Freitas, A. R. R., V. M. R. Silva, F. Campelo, and F. G. Guimarães. 2014. "Optimizing Two-Level Distribution Networks with Hybrid Memetic Algorithms." Optimization Letters 8 (2): 753-762. doi: 10.1007/s11590-013-0615-8.

[23] Vahdani, B., J. Razmi, and R. Tavakkoli-Moghaddam. 2012a. "Fuzzy Possibilistic Modeling for Closed Loop Recycling Collection Networks." Environmental Modeling \& Assessment 17 (6): 623-637. doi: 10.1007/s10666-012-9313-7.

[24] Pishvaee, M. S., and J. Razmi. 2012. "Environmental Supply Chain Network Design Using Multi-Objective Fuzzy Mathematical Programming.” Applied Mathematical Modelling 36 (8): 3433-3446. doi: 10.1016/j.apm.2011.10.007.

[25] Amin, S. H., and G. Zhang. 2012. "An Integrated Model for ClosedLoop Supply Chain Configuration and Supplier Selection: MultiObjective Approach." Expert Systems with Applications 39 (18): 6782-6791. doi:10.1016/j.eswa.2011.12.056.

[26] Lee, J.-E., K.-Y. Chung, K.-D. Lee, and M. Gen. 2013. “A MultiObjective Hybrid Genetic Algorithm to Minimize the Total Cost and Delivery Tardiness in a Reverse Logistics." Multimedia Tools and Applications. doi: 10.1007/s11042-013-1594-6.

[27] Vahdani, B., R. Tavakkoli-Moghaddam, M. Modarres, and A. Baboli. 2012b. "Reliable Design of a Forward/Reverse Logistics Network under Uncertainty: A Robust-M/M/c Queuing Model.” Transportation Research Part E 48 (6): 1152-1168. doi: 10.1016/j.tre.2012.06.002.

[28] Mehrbod, M., N. Tu, L. Miao, and D. Wenjing. 2012. "Interactive Fuzzy Goal Programming for a Multi-Objective Closed-Loop Logistics Network.” Annals of Operations Research 201 (1): 367-381. doi: 10.1007/s10479-012-1192-4.

[29] Zarandi, M. H. F., A. H. Sisakht, and S. Davari. 2011. "Design of a Closed-Loop Supply Chain (CLSC) Model Using an Interactive Fuzzy Goal Programming." The International Journal of Advanced Manufacturing Technology 56 (5-8): 809-821. doi: 10.1007/s00170011-3212-y. 
[30] Selim, H., and I. Ozkarahan. 2008. "A Supply Chain Distribution Network Design Model: An Interactive Fuzzy Goal ProgrammingBased Solution Approach.” The International Journal of Advanced Manufacturing Technology 36 (3-4): 401-418. doi: 10.1007/s00170006-0842-6.

[31] Golebiewski, B., J. Trajer, M. Jaros, and R. Winiczenko. 2013. "Modelling of the Location of Vehicle Recycling Facilities: A Case Study in Poland." Resources, Conservation and Recycling 80: 10-20. doi:10.1016/j.resconrec.2013.07.005.

[32] Dehghanian, F., and S. Mansour. 2009. "Designing Sustainable Recovery Network of End-Of-Life Products Using Genetic Algorithm." Resources, Conservation and Recycling 53 (10): 559570. doi: 10.1016/j.resconrec.2009.04.007.

[33] Li, J., M. González, and Y. Zhu. 2009. "A Hybrid Simulation Optimization Method for Production Planning of Dedicated Remanufacturing." International Journal of Production Economics 117 (2): 286-301. doi:10.1016/j.ijpe.2008.11.005.

[34] Diabat, A., R. Khodaverdi, and L. Olfat. 2013. "An Exploration of Green Supply Chain Practices and Performances in an Automotive Industry." The International Journal of Advanced Manufacturing Technology 68 (1-4): 949-961. doi: 10.1007/s00170-013-4955-4.

[35] Soleimani, H., M. Seyyed-Esfahani, and M. A. Shirazi. 2013. "Designing and Planning a Multi-Echelon Multi-Period Multi-Product Closed-Loop Supply Chain Utilizing Genetic Algorithm." The International Journal of Advanced Manufacturing Technology 68 (14): 917-931. doi: 10.1007/s00170-013-4953-6

[36] Mirakhorli, A. 2014. "Fuzzy Multi-Objective Optimization for Closed Loop Logistics Network Design in Bread-Producing Industries." The International Journal of Advanced Manufacturing Technology 70 (14): 349-362. doi: 10.1007/s00170-013-5264-7.

[37] Chern, C.-C., S.-T. Lei, and K.-L. Huang. 2014. "Solving a MultiObjective Master Planning Problem with Substitution and a Recycling Process for a Capacitated Multi-Commodity Supply Chain Network." Journal of Intelligent Manufacturing 25 (1): 1-25. doi:10.1007/s10845-012-0667-0.

[38] Zhou, X.-C., Z.-X. Zhao, K.-J. Zhou, and C.-H. He. 2012. "Remanufacturing Closed-Loop Supply Chain Network Design Based on Genetic Particle Swarm Optimization Algorithm." Journal of Central South University 19 (2): 482-487. doi: 10.1007/s11771-0121029-y.

[39] Jamshidi, R., S. M. T. Fatemi Ghomi, and B. Karimi. 2012. "MultiObjective Green Supply Chain Optimization with a New Hybrid Memetic Algorithm Using the Taguchi Method." Scientia Iranica Transactions E: Industrial Engineering 19 (6): 1876-1886. doi: 10.1016/j.scient.2012.07.002.

[40] Eskandarpour, M., E. Nikbakhsh, and S. H. Zegordi. 2013b. "Variable Neighborhood Search for the Bi-Objective Post-Sales Network Design Problem: A Fitness Landscape Analysis Approach." Computers \& Operations Research 52 (PB): 300-314. doi: 10.1016/j.cor.2013.06.002.

[41] Du, F., and G. W. Evans. 2008. "A Bi-Objective Reverse Logistics Network Analysis for Post-Sale Service." Computers \& Operations Research 35 (8): 2617-2634. doi: 10.1016/j.cor.2006.12.020.

[42] Subramanian, P., N. Ramkumar, T. T. Narendran, and K. Ganesh. 2013. "PRISM: PRIority Based SiMulated Annealing for a Closed Loop Supply Chain Network Design Problem.” Applied Soft Computing 13 (2): 1121-1135. doi: 10.1016/j.asoc.2012.10.004.

[43] Pishvaee, M. S., K. Kianfar, and B. Karimi. 2010b. "Reverse logistics Network Design Using Simulated Annealing." The International Journal of Advanced Manufacturing Technology 47 (1-4): 269-281. doi: $10.1007 / \mathrm{s} 00170-009-2194-5$.

[44] Lee, D.-H., and M. Dong. 2008. "A Heuristic Approach to Logistics Network Design for End-of-Lease Computer Products Recovery." Transportation Research Part E 44 (3): 455-474. doi: 10.1016/j.tre.2006.11.003.

[45] Schweiger, K., and R. Sahamie. 2013. "A Hybrid Tabu Search Approach for the Design of a Paper Recycling Network." Transportation Research Part E 50: 98-119. doi: 10.1016/j.tre.2012.10.006

[46] Bachlaus, M., M. K. Pandey, C. Mahajan, R. Shankar, and M. K. Tiwari. 2008. "Designing an Integrated Multi-Echelon Agile Supply Chain Network: A Hybrid Taguchi-Particle Swarm Optimization Approach.” Journal of Intelligent Manufacturing 19 (6): 747-761. doi:10.1007/s10845-008-0125-1.
[47] Tao, Z., Tian, W.-X., Zhang, Y.-J. and Liu, S.-X. 2008. "Improved Ant Colony System for VRPSPD with Maximum Distance Constraint." Systems Engineering-Theory \& Practice 28 (1): 132-140. doi: 10.1016/S1874-8651(09)60008-9.

[48] Wang, H.-F., and Y.-Y. Chen. 2012. "A Genetic Algorithm for the Simultaneous Delivery and Pickup Problems with Time Windows." Computers \& Industrial Engineering 62 (1): 84-95. doi: 10.1016/j.cie.2011.08.018.

[49] Aras, N., D. Aksen, and M. T. Tekin. 2011. "Selective Multi-Depot Vehicle Routing Problem with Pricing." Transportation Research Part $\begin{array}{llll}\text { C: } & \text { Emerging } & \text { Technologies } 19 & \text { (5): 866-884. }\end{array}$ doi:10.1016/j.trc.2010.08.003.

[50] Liu, S.-C., and C.-H. Chung. 2009. "A Heuristic Method for the Vehicle Routing Problem with Backhauls and Inventory." Journal of Intelligent Manufacturing 20 (1): 29-42. doi: 10.1007/s10845-0080101-9.

[51] Hemmelmayr, V., K. F. Doerner, R. F. Hartl, and S. Rath. 2013. "A Heuristic Solution Method for Node Routing Based Solid Waste Collection Problems." Journal of Heuristics 19: 129-156. doi: 10.1007/s10732-011-9188-9.

[52] Wassan, N. A., A. H. Wassan, and G. Nagy. 2008b. "A Reactive Tabu Search Algorithm for the Vehicle Routing Problem with Simultaneous Pickups and Deliveries." Journal of Combinatorial Optimization 15 (4): 368-386. doi: 10.1007/s10878-007-9090-4.

[53] Mar-Ortiz, J., J. L. González-Velarde, and B. Adenso-Díaz. 2013. "Designing Routes for WEEE Collection: The Vehicle Routing Problem with Split Loads and Date Windows.” Journal of Heuristics 19 (2): 103-127. doi: 10.1007/s10732-011-9159-1.

[54] Gajpal, Y., and P. Abad. 2009. "An Ant Colony System (ACS) for Vehicle Routing Problem with Simultaneous Delivery and Pickup." Computers \& Operations Research 36 (12): 3215-3223. doi: 10.1016/j.cor.2009.02.017.

[55] Çatay, B. 2010. "A New Saving-Based Ant Algorithm for the Vehicle Routing Problem with Simultaneous Pickup and Delivery." Expert Systems with Applications 37 (10): 6809-6817. doi: 10.1016/j.eswa.2010.03.045.

[56] Mingyong, L., and C. Erbao. 2010. "An Improved Differential Evolution Algorithm for Vehicle Routing Problem with Simultaneous Pickups and Deliveries and Time Windows." Engineering Applications of Artificial Intelligence 23 (2): 188-195. doi: 10.1016/j.engappai.2009.09.001

[57] Wassan, N. A., G. Nagy, and S. Ahmadi. 2008a. "A Heuristic Method for the Vehicle Routing Problem with Mixed Deliveries and Pickups." Journal of Scheduling 11 (2): 149-161. doi: 10.1007/s10951-0080055 -y.

[58] Nagy, G., N. A. Wassan, and S. Salhi. 2013. "The Vehicle Routing Problem with Restricted Mixing of Deliveries and Pickups." Journal of Scheduling 16 (2): 199-213. doi: 10.1007/s10951-012-0296-7.

[59] Kim, H., J. Yang, and K.-D. Lee. 2009. "Vehicle Routing in Reverse Logistics for Recycling End-of-Life Consumer Electronic Goods in South Korea." Transportation Research Part D 14 (5): 291-299. doi: 10.1016/j.trd.2009.03.001

[60] Belmecheri, F., C. Prins, F. Yalaoui, and L. Amodeo. 2013. "Particle Swarm Optimization Algorithm for a Vehicle Routing Problem with Heterogeneous Fleet, Mixed Backhauls, and Time Windows.” Journal of Intelligent Manufacturing 24 (4): 775-789. doi: 10.1007/s10845012-0627-8.

[61] Ai, T. J., and V. Kachitvichyanukul. 2009. "A Particle Swarm Optimization for the Vehicle Routing Problem with Simultaneous Pickup and Delivery." Computers \& Operations Research 36 (5): 1693-1702. doi:10.1016/j.cor.2008.04.003.

[62] Kassem, S., and M. Chen. 2013. "Solving Reverse Logistics Vehicle Routing Problems with Time Windows." The International Journal of Advanced Manufacturing Technology 68 (1-4): 57-68. doi: $10.1007 / \mathrm{s} 00170-012-4708-9$.

[63] Ganesh, K., and T. T. Narendran. 2008. "TASTE: A Two-Phase Heuristic to Solve a Routing Problem with Simultaneous Delivery and Pick-Up." The International Journal of Advanced Manufacturing Technology 37 (11-12): 1221-1231. doi: 10.1007/s00170-007-1056-2.

[64] Senthil, S., B. Srirangacharyulu, and A. Ramesh. 2012. "A Decision Making Methodology for the Selection of Reverse Logistics Operating Channels." Procedia Engineering 38: 418-428. doi: 10.1016/j.proeng.2012.06.052 
[65] Wei, J., and J. Zhao. 2013. "Reverse Channel Decisions for a Fuzzy Closed-Loop Supply Chain.” Applied Mathematical Modelling 37 (3): 1502-1513. doi: 10.1016/j.apm.2012.04.003.

[66] Yeh, W.-C., and M.-C. Chuang. 2011. "Using Multi-Objective Genetic Algorithm for Partner Selection in Green Supply Chain Problems." Expert Systems with Applications 38 (4): 4244-4253. doi: 10.1016/j.eswa.2010.09.091.

[67] Chiou, C. Y., H. C. Chen, C. T. Yu, and C. Y. Yeh. 2012. "Consideration Factors of Reverse Logistics Implementation - A Case Study of Taiwan's Electronics Industry." Procedia - Social and behavioral Sciences 40: 375-381. doi:10.1016/j.sbspro.2012.03.203.

[68] Kumar, V. V., F. W. Liou, S. N. Balakrishnan, and V. Kumar. 2013. "Economical Impact of RFID Implementation in Remanufacturing: A Chaos-Based Interactive Artificial Bee Colony Approach.” Journal of Intelligent Manufacturing. doi: 10.1007/s10845-013-0836-9.

[69] Wadhwa, S., J. Madaan, and F. T. S. Chan. 2009. "Flexible Decision Modeling of Reverse Logistics System: A Value Adding MCDM Approach for Alternative Selection." Robotics and Computer$\begin{array}{llll}\text { Integrated Manufacturing } 25 & \text { (2): } 460-469 . & \text { doi: }\end{array}$ 10.1016/j.rcim.2008.01.006.

[70] Efendigil, T., S. Önüt, and E. Kongar. 2008. "A Holistic Approach for Selecting a Third-Party Reverse Logistics Provider in the Presence of Vagueness." Computers \& Industrial Engineering 54 (2): 269-287. doi: 10.1016/j.cie.2007.07.009.

[71] Trappey, A. J. C., C. V. Trappey, and C.-R. Wu. 2010. "Genetic Algorithm Dynamic Performance Evaluation for RFID Reverse Logistic Management." Expert Systems with Applications 37 (11): 7329-7335. doi: 10.1016/j.eswa.2010.04.026.

[72] Kannan, G., S. Pokharel, and P. S. Kumar. 2009. "A Hybrid Approach Using ISM and Fuzzy TOPSIS for the Selection of Reverse Logistics Provider." Resources, Conservation and Recycling 54 (1): 28-36. doi: 10.1016/j.resconrec.2009.06.004.

[73] Olugu, E. U., and K. Y. Wong. 2012. "An Expert Fuzzy Rule-Based System for Closed-Loop Supply Chain Performance Assessment in the Automotive Industry." Expert Systems with Applications 39 (1): 375-384. doi: 10.1016/j.eswa.2011.07.026.

[74] Liu, B., Yin, M.-J., and Ma, S.-S. 2012. "Selection of ReverseLogistics Servicer for Electronic Products with Fuzzy Comprehensive Evaluation Method." Grey Systems: Theory and Application 2: 477482. doi: 10.1109/GSIS.2011.6044000.

[75] Tuzkaya, G., and B. Gülsün. 2008. "Evaluating Centralized Return Centers in a Reverse Logistics Network: An Integrated Fuzzy MultiCriteria Decision Approach.” International Journal of Environmental Science \& Technology 5 (3): 339-352. doi: 10.1007/BF03326029.

[76] Hu, H. Allen, S. H. Chen, C. W. Hsu, C. Wang, and C. L. Wu. 2012. "Development of Sustainability Evaluation Model for Implementing Product Service Systems." International Journal of Environmental Science and Technology 9 (2): 343-354. doi: 10.1007/s13762-0120037-7.

[77] Tuzkaya, G., A. Ozgen, D. Ozgen, and U. R. Tuzkaya. 2009. "Environmental Performance Evaluation of Suppliers: A Hybrid Fuzzy Multi-Criteria Decision Approach." International Journal of Environmental Science \& Technology 6 (3): 477-490. doi: 10.1007/BF03326087.

[78] Kara, S. S. 2011. "Evaluation of Outsourcing Companies of Waste Electrical and Electronic Equipment Recycling." International Journal of Environmental Science \& Technology 8 (2): 291-304. doi: 10.1007/BF03326217.

[79] Kannan, G. 2009. "Fuzzy Approach for the Selection of Third Party Reverse Logistics Provider." Asia Pacific Journal of Marketing and Logistics 21 (3): 397-416. doi: 10.1108/13555850910973865.

[80] Chuang, S.-P. 2014. "Assessing and Improving the Green Performance Using a Compound Approach." Flexible Services and Manufacturing Journal 26 (1-2): 69-91. doi:10.1007/s10696-0129156-1.

[81] Roy, A., K. Maity, S. Kar, and M. Maiti. 2009. "A ProductionInventory Model with Remanufacturing for Defective and Usable Items in Fuzzy-Environment." Computers \& Industrial Engineering 56 (1): 87-96. doi: 10.1016/j.cie.2008.04.004.

[82] Vadde, S., A. Zeid, and S. V. Kamarthi. 2011. "Pricing Decisions in a Multi-Criteria Setting for Product Recovery Facilities.” Omega 39 (2): 186-193. doi: 10.1016/j.omega.2010.06.005

[83] Adenso-Díaz, B., S. García-Carbajal, and S. M. Gupta. 2008. "A PathRelinking Approach for a Bi-Criteria Disassembly Sequencing
Problem." Computers \& Operations Research 35 (12): 3989-3997. doi:10.1016/j.cor.2007.06.002.

[84] Kalayci, C. B., and S. M. Gupta. 2013a. "Ant Colony Optimization for Sequence-Dependent Disassembly Line Balancing Problem." Journal of Manufacturing Technology Management 24 (3): 413-427. doi: 10.1108/17410381311318909.

[85] Zhang, J., X. Liu, and Y. L. Tu. 2011. "A Capacitated Production Planning Problem for Closed-Loop Supply Chain with Remanufacturing." The International Journal of Advanced Manufacturing Technology 54 (5-8): 757-766. doi: 10.1007/s00170010-2948-0

[86] Krapp, M., J. Nebel, and R. Sahamie. 2013. "Using Forecasts and Managerial Accounting Information to Enhance Closed-Loop Supply Chain Management." OR Spectrum 35 (4): 975-1007. doi: 10.1007/s00291-013-0345-4.

[87] Barba-Gutiérrez, Y., and B. Adenso-Díaz. 2009. "Reverse MRP Under Uncertain and Imprecise Demand." The International Journal of Advanced Manufacturing Technology 40 (3): 413-424. doi:10.1007/s00170-007-1351-y.

[88] Kalayci, C. B., and S. M. Gupta. 2013b. "A Particle Swarm Optimization Algorithm with Neighborhood-Based Mutation for Sequence-Dependent Disassembly Line Balancing Problem." The International Journal of Advanced Manufacturing Technology 69 (14): 197-209. doi: 10.1007/s00170-013-4990-1.

[89] Ding, L.-P., Y.-X. Feng, J.-R. Tan, and Y.-C. Gao. 2010. "A New Multi-Objective Ant Colony Algorithm for Solving the Disassembly Line Balancing Problem." The International Journal of Advanced Manufacturing Technology 48 (5-8): 761-771. doi: 10.1007/s00170009-2303-5.

[90] Tuncel, E., A. Zeid, S. Kamarthi. 2014. "Solving Large Scale Disassembly Line Balancing Problem with Uncertainty Using Reinforcement Learning." Journal of Intelligent Manufacturing 25 (4): 647-659. doi: 10.1007/s10845-012-0711-0.

[91] Wang, H.-F., and H.-W. Hsu. 2012. "A Possibilistic Approach to the Modeling and Resolution of Uncertain Closed-Loop Logistics." Fuzzy Optimization and Decision Making 11 (2): 177-208. doi: 10.1007/s10700-012-9120-2.

[92] Walther, G., E. Schmid, and T. S. Spengler. 2008. "Negotiation-Based Coordination in Product Recovery Networks." International Journal of $\begin{array}{lllll}\text { Production } & \text { Economics } 111 & \text { (2): 334-350. doi: }\end{array}$ 10.1016/j.ijpe.2006.12.069.

[93] Mishra, N., V. Kumar, and F. T. S. Chan. 2012. "A Multi-Agent Architecture for Reverse Logistics in a Green Supply Chain." International Journal of Production Research 50 (9): 2396-2406. doi: 10.1080/00207543.2011.581003.

[94] Prakash, PKS, D. Ceglarek, and M. K. Tiwari. 2012. "ConstraintBased Simulated Annealing (CBSA) Approach to Solve the Disassembly Scheduling Problem." The International Journal of Advanced Manufacturing Technology 60 (9-12): 1125-1137. doi: 10.1007/s00170-011-3670-2. 